Erratum

\title{
The molecular systematics of some agar- and carrageenan-containing marine red algae based on $r b c L$ sequence analysis
}

Suzanne Fredericq ${ }^{1,4}$, Max. H. Hommersand ${ }^{2}$ \& D. Wilson Freshwater ${ }^{3}$

${ }^{1}$ Department of Botany, Duke University, Durham, NC 27708-0338, USA

${ }^{2}$ Department of Biology, University of North Carolina, Chapel Hill, NC 27599-3280, USA

${ }^{3}$ Center for Marine Science Research, 7205 Wrightsville Avenue, Wilmington, NC 28403, USA

${ }^{4}$ Present address: Laboratory of Molecular Systematics and Department of Botany, NHB-166, National Museum of Natural History, Smithsonian Institution, Washington, DC 20560,USA; e-mail: Frederic@onyx.si.edu

Hydrobiologia 326/327: 125-135, 1996.

S. C. Lindstrom \& D. J. Chapman (eds), Fifteenth International Seaweed Symposium.

On p. 129 of the above article, Figure 3 was unfortunately omitted (a duplicate of Figure 2 appearing in its place). We now present Figure 3 below.

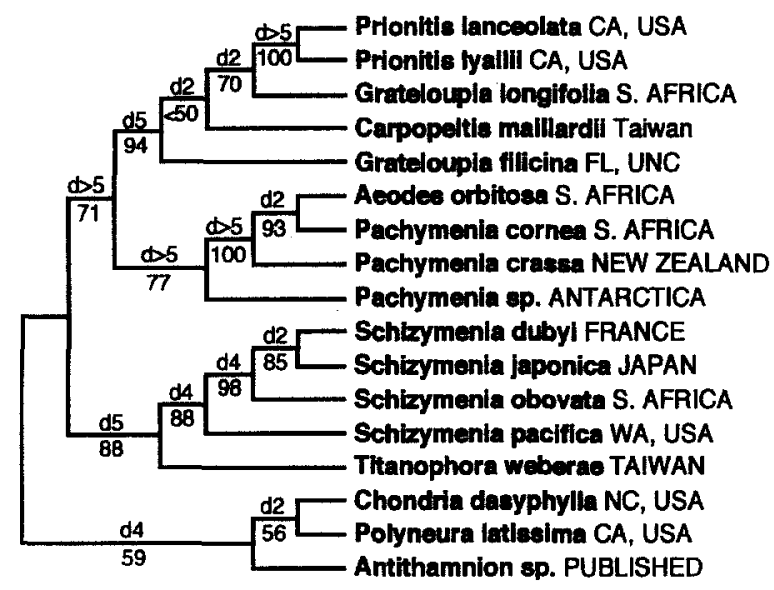

Figure 3. Single maximum parsimony tree of length $=803, \mathrm{CI}=$ 0.540 and $\mathrm{RI}=0.583$, resulting from a multiple heuristic search analysis of $r b c \mathrm{~L}$ sequence data from nine Halmeniaceae, five Schizymeniaceae and three Ceramiales (as outgroup) species. Decay indices are indicated above and bootstrap values (\%) below branches. 